Journal of Thermal Engineering, Vol. 5, No. 3, pp. 210-221, April, 2019

Yildiz Technical University Press, Istanbul, Turkey

\title{
RESPONSE SURFACE BASED OPTIMIZATION OF RIBBED ISOSCELES TRIANGULAR TWISTED TAPE HEAT EXCHANGER USING ENTROPY AUGMENTATION GENERATION NUMBER WITH $\mathrm{AL}_{2} \mathrm{O}_{3} \mathrm{NANO}$ WORKING FLUID
}

\author{
K. Pavan Kumar ${ }^{1 *}$, R. Siddhardha ${ }^{2}$, Ramabhadri Raju ${ }^{3}$, K. Sudheer Kumar ${ }^{1}$
}

\begin{abstract}
In this work, a combination of passive techniques like providing ribs on the duct surface, inserting twisted tapes were employed at different configurations and analysed using ANSYS Fluent 17.2. The enhancement is probed by placing ribs on the duct surfaces at various angles. Twisted tape inserts were used in conjunction with ribs on the duct and an output parameter, Entropy Augmentation Generation Number (EAGN) is analysed when having an $\mathrm{Al}_{2} \mathrm{O}_{3}$ nanofluid $(\phi=3 \%)$ as working medium. In furtherance, tapes of isosceles triangular projections with variable configuration, such as rib angles $\left(30^{\circ}<\alpha<90^{\circ}\right)$, Internal angle $\left(30^{\circ}<\beta<90^{\circ}\right)$ and projection distance $(1 \mathrm{~mm}<\mathrm{x}<5 \mathrm{~mm})$ were also inserted in place of plain twisted tape inserts to verify the enhancement promised by this alteration. As expected, rate of heat transfer due to the presence of isosceles triangle projections gave decent augmentation. Later Response Surface based optimization was employed with non-parametric regression and genetic algorithm to make an investigative search of all the modified parameters so as to suggest best blend of inputs for low Entropy Augmentation Generation Number. Optimum performance was obtained at rib angle of $30^{\circ}$, projection distance of $2.1 \mathrm{~mm}$ and Internal angle of $44.4^{\circ}$ with entropy augmentation number value of 0.77 . The performance of Genetic Algorithm was compared with Micro Genetic Algorithm; it shows that optimized result is obtained less than half the time using Micro Genetic Algorithm.
\end{abstract}

Keywords: Ribs, Isosceles Triangular Projections, Entropy Augmentation Generation Number, Non Parametric Regression, Genetic Algorithm, Micro Genetic Algorithm

\section{INTRODUCTION}

In many process industries viscous fluids are used in heat exchangers. Due to low heat transfer coefficient in laminar flow, active or passive heat transfer augmentation techniques are needed to be implemented. This implementation generally reduces size and cost of heat exchanger. The additional advantage of reducing temperature of the fluid can be obtained by increasing the heat transfer coefficient, and by doing this there is a decrease in entropy generation. The pressure drop identified in a heat exchanger is one of the reasons for enhancement in internal heat generation. The combination of heat transfer and pressure drop is postulated in Entropy Augmentation Generation Number (EAGN) based on second law of thermodynamics.

The Performance of Heat exchanger can be enhanced by using twisted tape passive technique [1-8].Swirl induced heat transfer enhancement will increase the frictional losses and hence increasing the pumping power. Attempts have been made to reduce the frictional losses by several approaches [9] using loose fit twisted tape. Eiamsaard et.al [10] has suggested that in twisted tape heat exchanger space ratio (free space length to tube diameter) should be maintained less than unity to reduce frictional losses and get better heat transfer rates.Jaisankaret.al [11] found that spacer at trailing edge of twisted tape reduces the frictional losses. Twisted tapes along with ribs have shown better performance than either of them [12]. Saha SK et.al [13] has found that pinching of tapes in place has shown marginal increase in thermo hydraulic performance than that connecting with rods for twisted tape. Experimental Investigation of heat transfer and pressure drop characteristics are reported for square ducts with ribs for short and full length twisted

This paper was recommended for publication in revised form by Regional Editor Sandip Kale

${ }_{1}^{1}$ Department of Mechanical Engineering (MCT), M.G.I.T., Hyderabad, INDIA

${ }^{2}$ Department of Mechanical Engineering, G.V.P.S.O.E., Visakhapatnam, INDIA

${ }^{3}$ Department of Mechanical Engineering, S.R.K.R., Bhimavaram, INDIA

${ }^{\star} E$-mail address: pavankonchada@gmail.com

Orcid id: 0000-0002-6269-9238, 0000-0002-4629-9058, 0000-0003-3485-9940, 0000-0002-1527-2530

Manuscript Received 05 December 2017, Accepted 17 April 2018 
tapes. Regularly spaced twisted-tape elements proved to be better than short-length ones when their performance is evaluated [14]. Pathipakka et.al [15] numerically investigated the heat transfer characteristics for circular tube with nano fluid. Enhancement of $31.29 \%$ was found with helical twist ratio 2.93 together with $\mathrm{Al}_{2} \mathrm{O}_{3}$ nanofluid with $1.5 \%$ volume concentration at 2039 Reynolds number compared to base fluid. A significant improvement of the average Nusselt number was obtained for angled ribs in anti-periodic configuration[16]. This improvement can be attributed to the formation of longitudinal vortices that mix near wall and center flows.

Longitudinal finned tube heat exchanger performance with shell side nano fluid is evaluated using the $2^{\text {nd }}$ law of thermodynamics for performance evaluation and the usage of nanofluid has improved the efficiency [17].Performance evaluation of single and three start spirally corrugated tube twisted tape heat exchanger is performed using EAGN for five different pitches and varying the characteristic parameters like diameter and height of the tapes has shown that the heat transfer rate has increased[18, 19].Natural convection process is analyzed based on entropy augmentation generation number [27, 28].

From the literature review it is obvious that different geometry of twisted tape and transverse ribs can enhance the heat transfer, it is evident from above literature that analysis is carried on circular tube having helical twisted tape inserts with $\mathrm{Al}_{2} \mathrm{O}_{3}$ nano fluid as working fluid [15] and ribs of different configurations [12]. But Geometric variations in helical twisted tape and ribbed ducts with nanofluid as working fluid were not present in the previous works. Therefore it is enthralled to potential in enhancement of heat transfer for newly designed twisted tape and ribs on duct with promising geometry. In the present work twisted tape with Isosceles triangular projections (ITP) inserted in a square ductwith staggered ribs are evaluated for $\mathrm{Al}_{2} \mathrm{O}_{3}$ nano fluid $(\phi=3 \%)$ as working fluid for Reynolds number 100400.It is evident that the presence of $\mathrm{Al}_{2} \mathrm{O}_{3}$ nano particles in fluid decreases the EAGN [26] which indicates the augmentation of heat exchanger efficiency. The combination of twisted tape heat exchanger and entropy augmentation generation number has been less researched in conjunction with each other which has formed the impetus of the present research. The different configurationsof modified twisted tape and duct is designed to have better swirl motion along the tube which is expected to provide better mixing. The configuration optimization was performed based on entropy augmentation generation number using Neuro-Genetic Algorithm.

\section{NUMERICAL SIMULATION Problem Formulation}

In the current work passive augmented technique employed is the change of cross section of twisted tape. It is done by reducing the thickness of tape from $2 \mathrm{~mm}$ to $1 \mathrm{~mm}$, the decrement in thickness is compensated with triangular projections on tape. Different included angles and distances between projections are considered for simulation by maintaining constant surface area. In addition to modification done to twisted tape, ribs are also placed on the duct [16] for augmented geometry.

A layout of square duct with cross sectionH $\times \mathrm{S}(13 \times 13 \mathrm{~mm})$ and length $62 \mathrm{~mm}$ with three numbers of staggered ribs of depth $\mathrm{H} / 10$ [16] at different anglesis considered as shown in Figure 1.Cross section of ITP twisted tape having a constant twist ratio $(\mathrm{y} / \mathrm{w}=2.88)$ with variable internal angleand projections distance is as shown in Figure 2.The Three independent parameters considered for the present work are
1) Rib angle $\left(30^{\circ}<\alpha<90^{\circ}\right)$
2) Internal Angle $\left(30^{0}<\beta<90^{0}\right)$
3) Projection Distance $(1 \mathrm{~mm}<\mathrm{x}<5 \mathrm{~mm})$

\section{Mathematical Model}

A three dimensional numerical simulation of entropy augmentation generation was conducted by ANSYS FLUENT 15.The Governing differential equation 'Continuity equation' derived from conservation of mass principle, the 'Momentum or Navier-Stokes equation' derived from conservation of momentum principle and the 'Energy equation' derived from conservation of energy principle were the three conservation principles used in building the mathematical model. These fundamental equations along with appropriate initial conditions and boundary conditions were solved to understand various fluid and heat flow characteristics prevailing in the heat exchanger. 
Journal of Thermal Engineering, Research Article, Vol. 5, No. 3, pp. 210-221, April, 2019

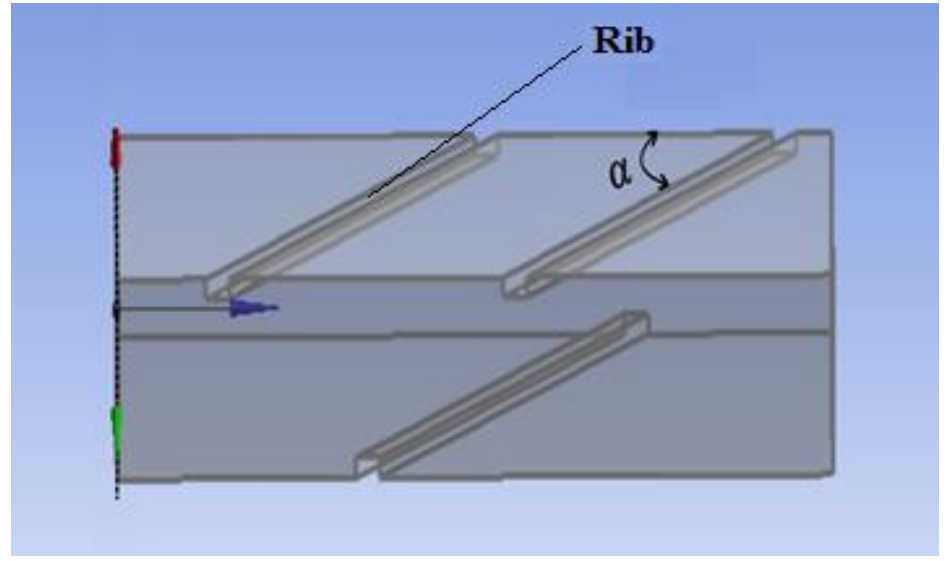

Figure 1.Modelling of duct

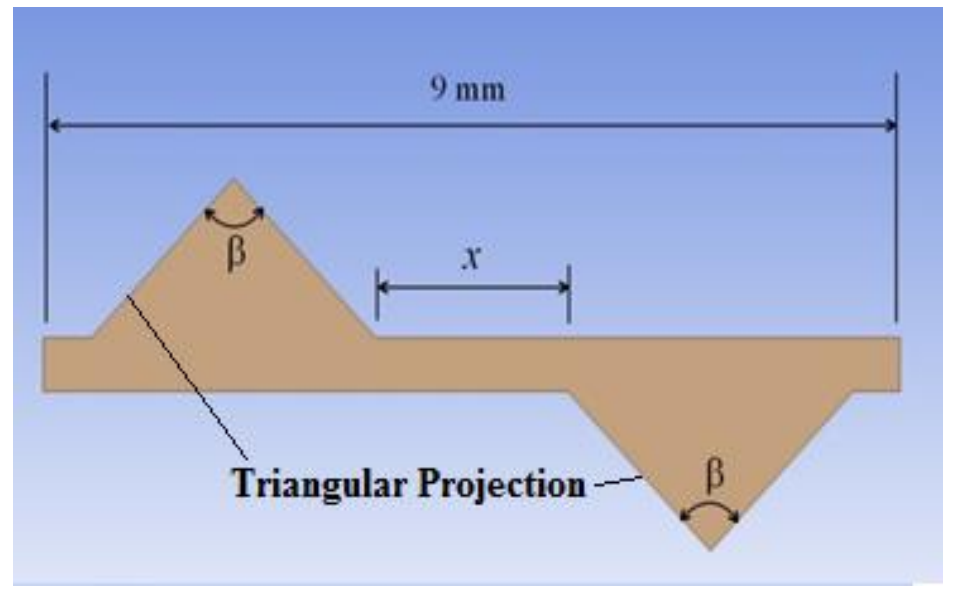

Figure 2. Cross section of twisted tape

The continuity equation given for steady state flow of a compressible fluid is

$$
\frac{\partial\left(\rho U_{i}\right)}{\partial x_{i}}=0
$$

The momentum equation given for steady state flow of a compressible fluid is

$$
U_{j} \frac{\partial\left(\rho U_{i}\right)}{\partial x_{j}}=-\frac{\partial P}{\partial x_{i}}+\frac{\partial}{\partial x_{j}}\left((\mu) \cdot \frac{\partial\left(\rho U_{i}\right)}{\partial x_{j}}\right)
$$

The energy equation given for steady state flow of a compressible fluid is

$$
C_{p} U_{j} \frac{\partial(\rho T)}{\partial x_{j}}=\frac{\partial}{\partial x_{j}}\left((k) \cdot \frac{\partial(\rho T)}{\partial x_{j}}\right)
$$

Nanofluid used in the simulation is considered as single phase with equivalent thermo physical properties [17] of two phase fluids. These thermo physical properties were hooked as UDFs to the code.Discretization of convective term is done using the QUICK scheme and pressure velocity coupling by SIMPLE scheme. 


\section{Mesh Independence and Code Validation}

Mesh independence was carried out for different configurations of independent parameters $\alpha, \beta$ and xwith average Nusselt number as criteria. The mesh size is considered for further simulation study only if the Nusselt number variation is less than $1 \%$ for 9,25,768 tetrahedron mesh size. Code used in this study is validated with theexperimental correlations developed by Mallick and Saha [14]. The Nusselt numbers obtained from the Ansys Fluent 17.2 are of the same order and the error was within 5\% compared to correlations.

\section{Boundary Conditions and Solution Procedure}

A constant heat flux $10000 \mathrm{w} / \mathrm{m}^{2}$ was applied on ribbed duct wall and no slip boundary condition was imposed on the wall. The inlet and outlet of the ITP ribbed duct was made periodic by converting them into interface to make the flow fully developed. A mass flow rate corresponding to different Reynolds number is given as input periodic flow condition. The wall of ITP twisted tape is kept as adiabatic. A convergence criteria of $10^{-6}$ is been set forcontinuity, momentum and energy equation.

\section{Entropy Augmentation Generation Number}

Entropy generation rate consists of two parts one "viscous" $\dot{s}_{v}$, depends on the physical viscosity, on the local temperature of the fluid and on the second power of the local velocity gradient, and another, called "thermal" $\dot{s_{T}}$, that depends on the physical conductivity, on the square of the local temperature of the fluid and on the second power of the local temperature gradient:

$$
\dot{S_{\text {gen }}}=\dot{S_{T}}+\dot{S_{v}}=\frac{k}{T^{2}}\left(\left(\frac{\partial T}{\partial x}\right)^{2}+\left(\frac{\partial T}{\partial y}\right)^{2}+\left(\frac{\partial T}{\partial z}\right)^{2}\right)+\frac{\emptyset}{T}
$$

In our case flow considered is laminar so the entropy generation due to viscous effects is neglected. Note that the entropy generation rate expressed in (4)is per unit volume $\left(\mathrm{W} /\left(\mathrm{m}^{3} \mathrm{~K}\right)\right)$. The global entropy generation rate $S_{g e n}^{\cdot}$ of the entire domain $(\mathrm{W} / \mathrm{K})$ is computed as the integral of the local rates over the entire volume

$$
S_{g e n}=\int_{v} S_{g e n} d v
$$

Bejan and Pfister [20] proposed that the merit of a given heat transfer augmentation technique may be evaluated by comparing the rate of entropy generation of the heat exchange apparatus before and after the implementation of the augmentation technique. Entropy generation augmentation number is given by [21-23]:

$$
N_{S, a}=\frac{S_{g e n, a}}{S_{g e n, o}}
$$

For $N_{s, a}<1$ passive techniques employed are thermodynamically advantageous augmentation technique because, in addition to enhancing heat transfer, they reduce the degree of irreversibility of the apparatus.

\section{OUTLINE OF RESPONSE SURFACE BASED OPTIMIZATION Non-Parametric Regression}

Non-parametric regression (NPR) is analgorithm which is initiated by any one of the available Design of Experiments (DOE) and can produce enhanced response quality. For present work, this NPR algorithm of ANSYS Design Xploreris used so as to handle higher non-linear behavior outputs with inputs. This technique uses hyper planes to segregate data groups and thus belongs to Support Vector Method (SVM) type techniques. Although the regression method works almost similarly, it differs in hyper plane which is used to categorize a subset (also called "support vector" set) of the input sample vectors which are adequatelyestimated to represent the output in question. In the current version, the internal parameters of the meta-model are fixed to constant values and are not optimized. 


\section{Genetic Algorithm}

The technique of Genetic algorithms (GA) is based onevolutionary ideas of natural selection and genetic [24] used for algorithms that take investigative search. The ideology of this algorithm is to rely on chromosome-like data structures for fetching out a possible and appropriate solution to the problem and to apply genetic operators to these structures accordingly [25].The algorithm starts with an initial set of populationencoded inbinary values $(0 \mathrm{~s}$ and 1s) and then decides the worth of a particular member by bringing its objective function value to comparison with that of other members in the population. This comparison is termed as fitness function and later to this; the three basic genetic operators viz., reproduction, crossover and mutation were performed. Reproduction is the selection procedure based on the fitness function of the members to mate them for generation of offsprings. Here members of higher fitness function were more likely to get selected and mated in accordance with Darwinian principal of survival of the fittest.

In crossover, the offsprings from reproduction were allowed to get partial alterations in their strings for generation of new strings under certain crossover probability.In order to bring disparity in the population, and to check the nearby points of the current solution, Mutation of population is exercised. This ensures that the local points surrounding the offsrings were also considered due toinduced mutation probability giving room for variability in population.Population size and the crossover fraction considered in this study is 100 and 0.8 respectively.

\section{Micro Genetic Algorithm}

The Micro-Genetic Algorithm ( $\mu \mathrm{GA}$ ) practices similar approach as that of Genetic Algorithm but for the population size. In $\mu \mathrm{GA}$, the population size is usually very less than Genetic Algorithm so that the computational time demanded for best fit solution is lessened. The population size considered in this work is 5 for each generation.

\section{RESULTS AND DISCUSSIONS}

The local entropy generation as indicated by the contours of Plain twisted tape heat exchanger at its mid spans'transverse section(Figure 3) has higher range of values manifestedto greater extent of cross-section when compared to ribbed ITP twisted tape heat exchanger (Figure 5).

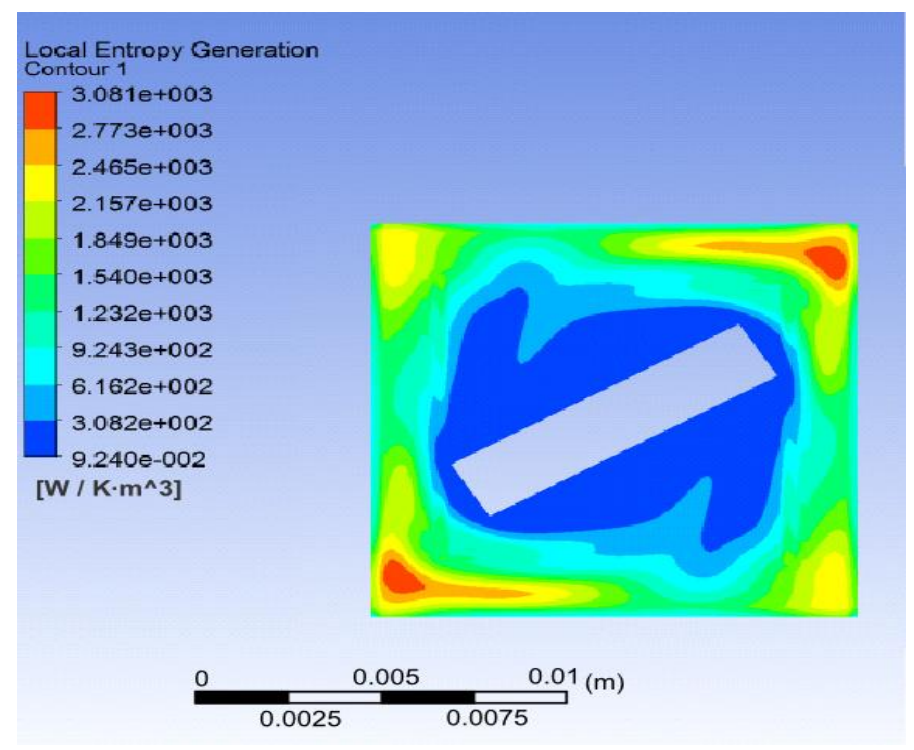

Figure 3. Transverse section of Plain twisted tape at $\mathrm{Re}=100$

The longitudinal section of Plain twisted tape heat exchanger portraits higher range of entropy generation values along the length at various sections (Figure 4) and the influence of higher entropy generation is felt to greater extent when compared to ribbed ITP twisted tape heat exchanger (Figure 6). The presence of ribs and projections of twisted tape ensure quick response in terms of swirl and thereby its influence surpassed the effect of shear and strain. 
Journal of Thermal Engineering, Research Article, Vol. 5, No. 3, pp. 210-221, April, 2019

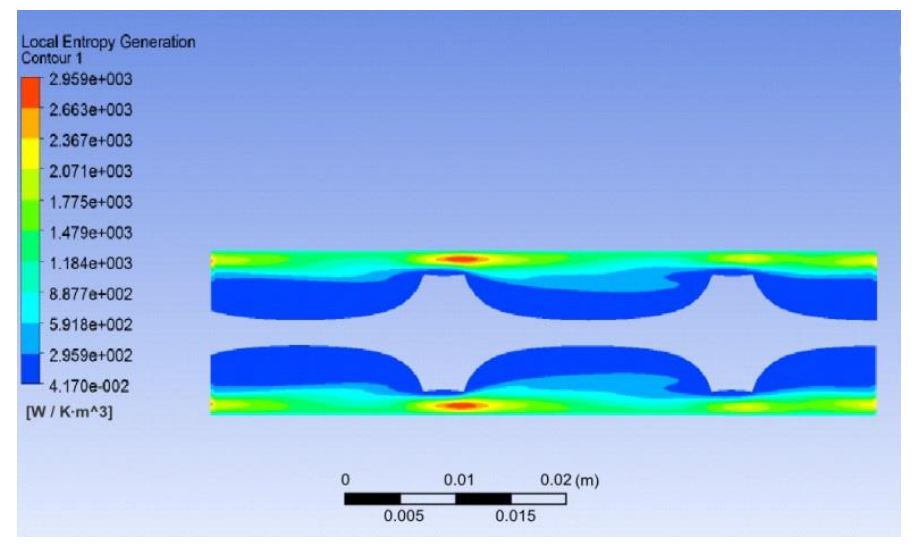

Figure 4. Longitudinal section of Plain twisted tape at $\mathrm{Re}=100$

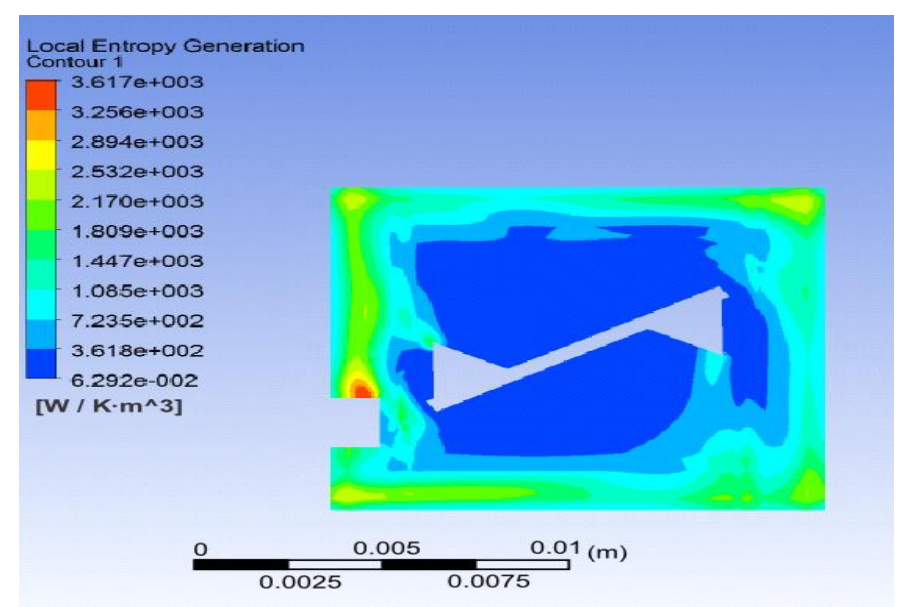

Figure 5. Transverse section of ribbed ITP twisted tape at $\mathrm{Re}=100$

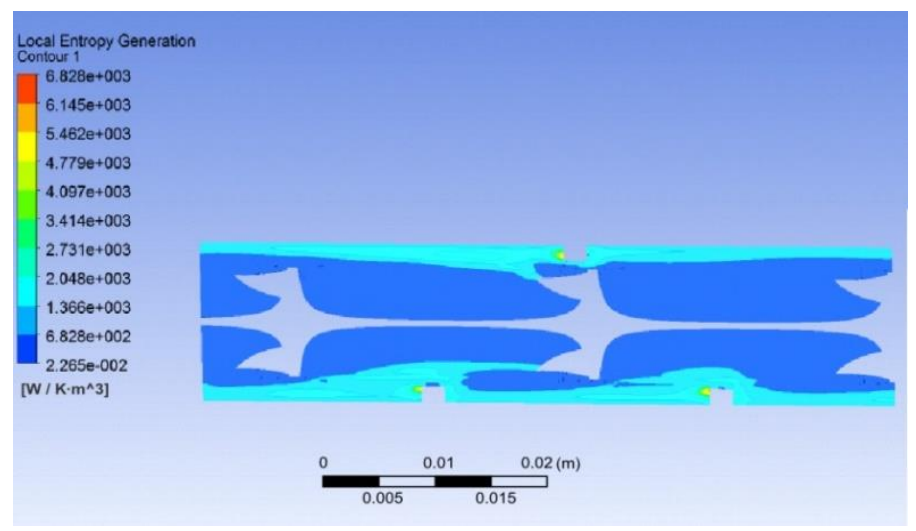

Figure 6. Longitudinal section of ribbed ITP twisted tape at $\mathrm{Re}=100$

Entropy Augmentation Generation number is low for lesser rib angle (Ns, $\mathrm{a}=0.8$ for $\alpha=60^{\circ}, \mathrm{Ns}, \mathrm{a}=0.815$ for $\alpha=90^{\circ}$ at $\mathrm{Re}=100$ ) by keeping remaining parameters constant due to the intense mixing of fluid as shown in Figure7.As the Rib angle decreases there is enhanced mixing of the fluid and more amount of heat will be extracted and get dispersed uniformly in the working fluid. Thus EAGN value decreases as the temperature gradient decreases. 
It can also be observed that as Reynolds number increases decrement in Ns,a is higher which indicates augmentation of efficiency of heat exchanger as Re increases.

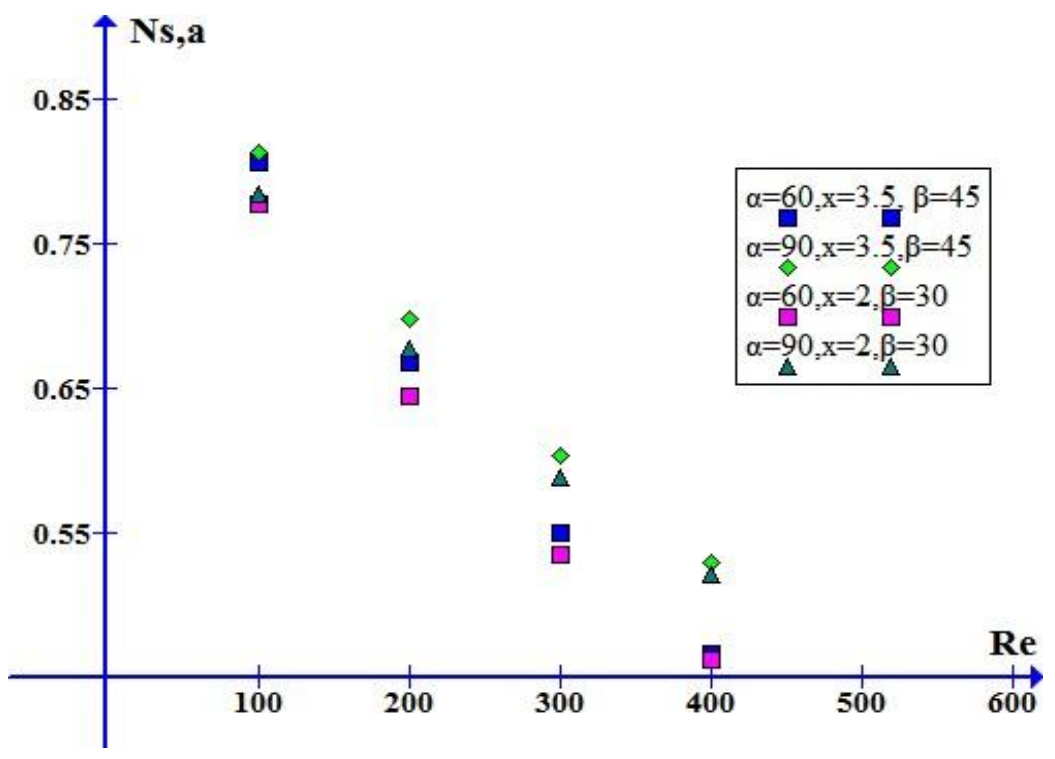

Figure 7. Effect Of Rib Angle on Ns,a

Variation in Internal angle don't have the profound effect on the Ns,a, however for smaller internal angle Ns, a decreases with increase in Re compared to higher angles. The above said is due to slight enhancement in intensity ofmixing (Figure 8) at higher Re values. It is evident from Figure 9 that projection distance have great impact on Ns,a at lower Reynolds number(Ns, $\mathrm{a}=0.78$ at $\mathrm{x}=2$ and $\mathrm{Ns}, \mathrm{a}=0.81$ at $\mathrm{x}=3.5$ for $\mathrm{Re}=100)$ and they are overlapping at Higher Reynolds number. It can also be noted that lower projection distance ensures better performance.

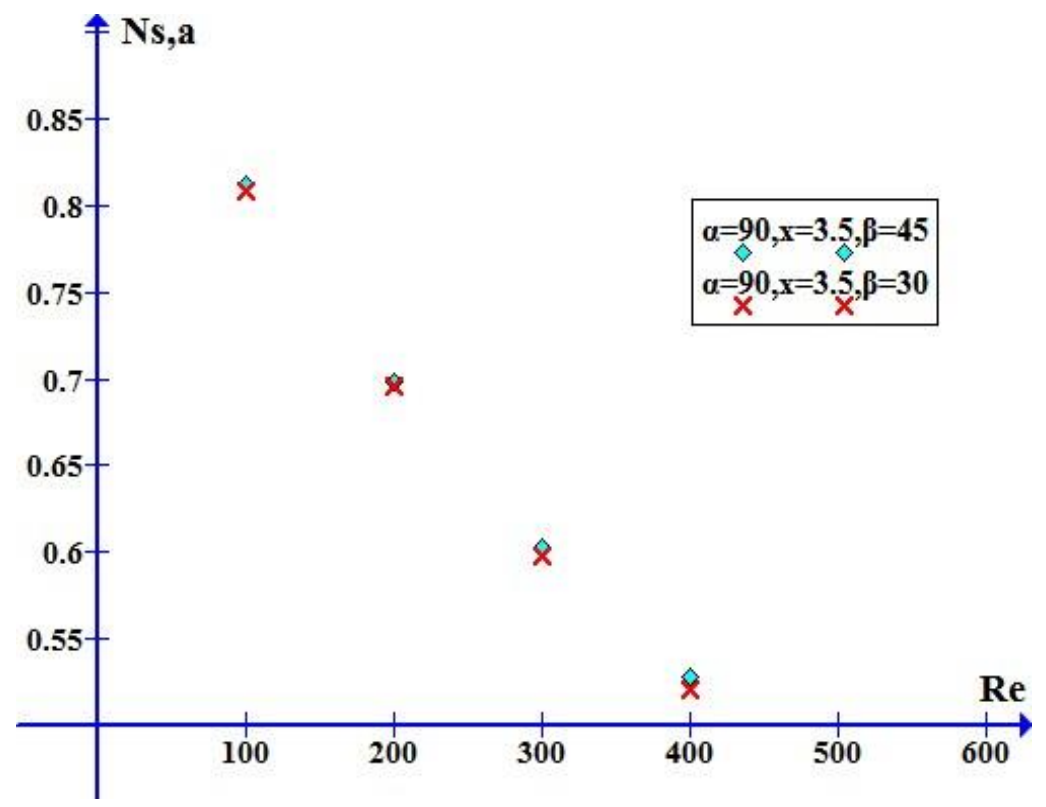

Figure 8. Effect of Internal Angle on Ns,a 


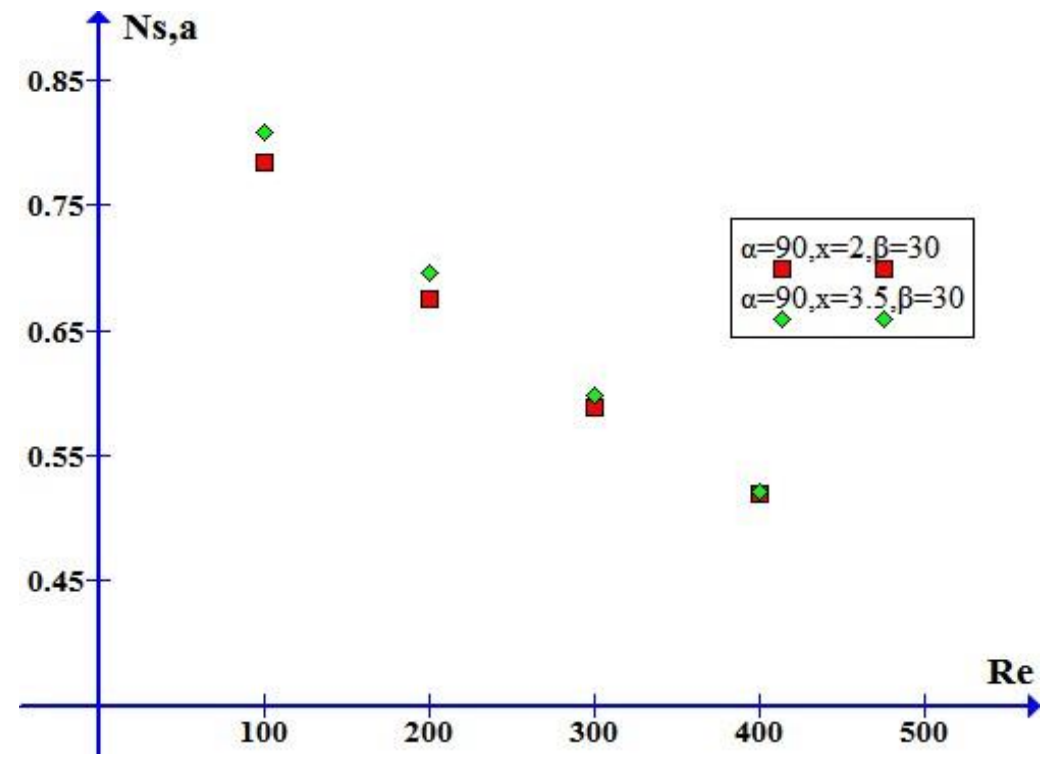

Figure 9. Effect of Projection Distance on Ns,a

\section{Response Surface Based Optimization}

A total of 50 simulation results for Reynolds number 100 and volume fraction of nanofluid $(\phi=3 \%)$ are fed into NPR by varying Rib angle, internal angle and Projection distance within considered range for response surface generation (Figure 11 and 12 ) in Ansys Design Xplorer. Figure 11 shows the combined interaction of projection distance on the twisted tape and rib angle of duct on Entropy augmentation generation number where the internal angle is kept at zero level $\left(\beta=60^{\circ}\right)$. It can be observed that EAGN decreases as both projection distance and rib angle decreases. Maximum EAGN is observed at $4 \mathrm{~mm}$ projection distance and $90^{\circ}$ rib angle and minimum is observed at in between 2 and $2.5 \mathrm{~mm}$ projection angle and $30^{\circ}$ rib angle. As shown in Figure 13 it can be observed that at projection distance of $2 \mathrm{~mm}$ and internal angle around $40^{\circ}$ gives the least EAGN on keeping the rib angle at zero level $\left(\alpha=60^{\circ}\right)$.

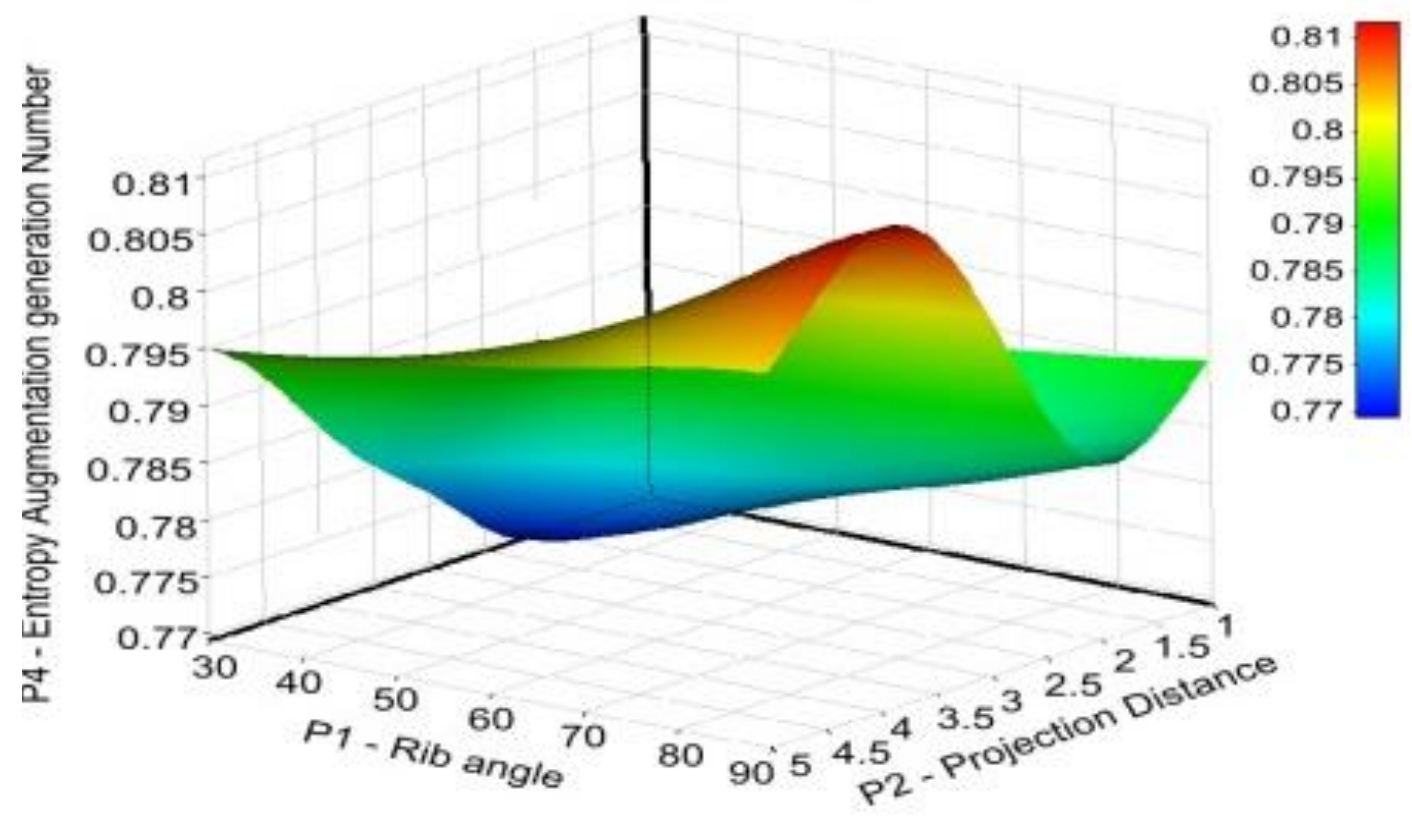

Figure 11. Response Surface For Rib angle and Projection Distance 


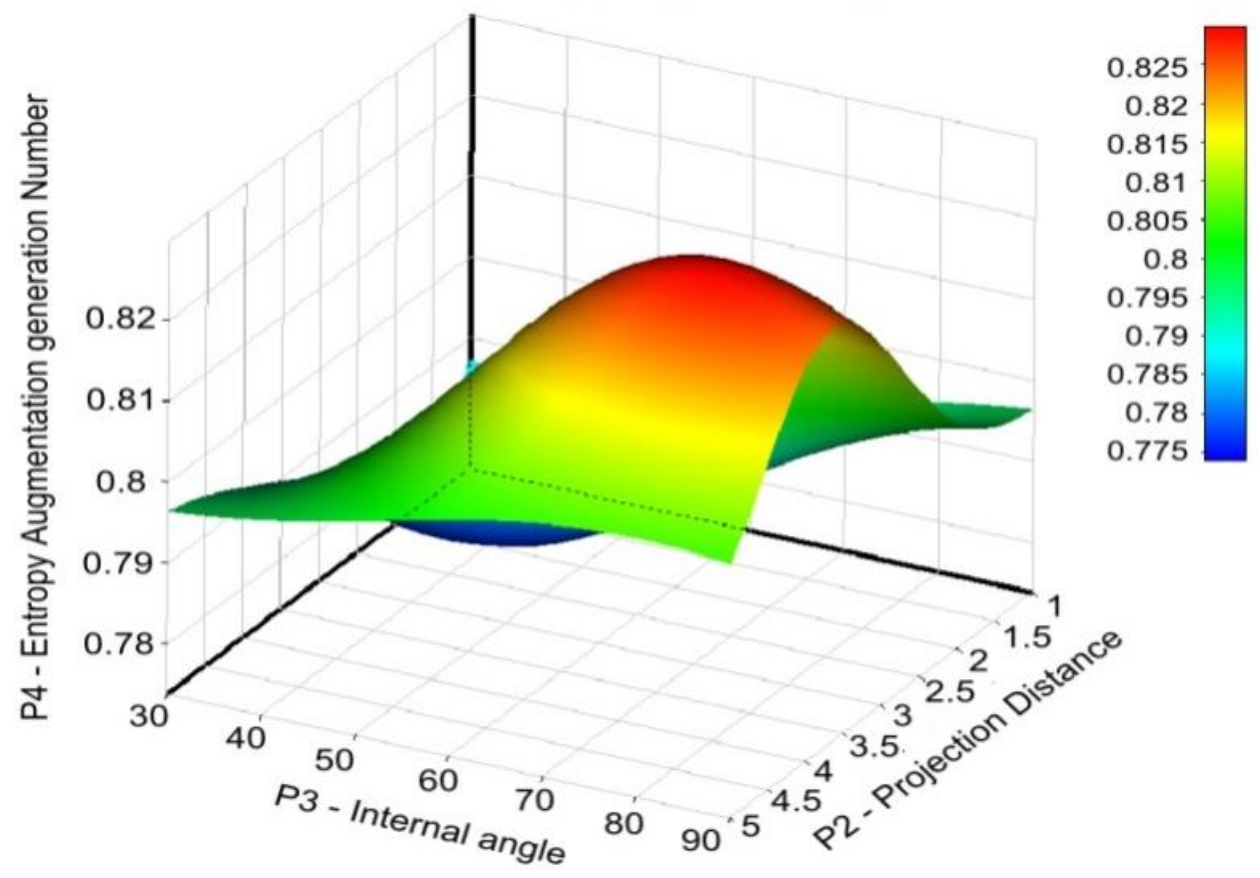

Figure 12. Response Surface For Internal angle and Projection Distance

\section{Results from $\mu \mathrm{GA}$ and GA integrated with Response Surface Generated by NPR}

The objective function is Minimization

$$
N_{s, a}=f(\alpha, \beta, x)
$$

Subjected to constraint

$$
\frac{\sqrt{(18 \sin \beta)}}{\cos (\beta / 2)}+x-9 \leq 0
$$

From the above NPR response surface 10000 points are fed into Genetic Algorithm of Response surface based optimization of the objective function.

The optimum values of Entropy Augmentation generation number value obtained from GA and Micro GA is 0.766 and 0.771 . The computational time has been reduced by more than half in micro GA with less variation in optimum values.

Table 1. The specified value of GA and Micro GA

\begin{tabular}{|c|c|c|c|c|c|}
\hline Type & RibAngle & $\begin{array}{c}\text { Projections Distance } \\
(\mathrm{mm})\end{array}$ & Internal Angle & $N_{s, a}$ & $\begin{array}{c}\text { Computational } \\
\text { Time }\end{array}$ \\
\hline GA & $30.1^{0}$ & 2.1097 & $44.4^{0}$ & 0.766 & 18 \\
\hline Micro GA & $30.643^{0}$ & 2.0007 & $44.371^{0}$ & 0.771 & 7 \\
\hline
\end{tabular}

\section{CONCLUSION}

The following are the conclusions drawn from the above study:

- Enhancement of performance escalates with increase in Reynolds number 
- As the Rib angle decreases EAGN decreases for any Reynolds number for without any variability in other parameters, and EAGN decrements more as Reynolds number increases

- Low internal angle in ITP has better enhancement and EAGN changeability is low as Reynolds number increases

- Projection Distance at lower Reynolds number has more impact on EAGN compared to higher Reynolds number

- EAGN values decreased within considered Reynolds number as Nano fluid volume fraction increased indicating the enhancement of performance of heat exchanger.

- At Rib angle $\left(30^{\circ}\right)$,Projection Distance $(2.1 \mathrm{~mm})$ and Internal Angle $\left(44.4^{\circ}\right)$ an optimized result of $N_{s, a}=$ 0.766 is obtained

- The decremented computational time in using micro GA rather than GA is slightly more than half

\section{NOMENCLATURE}

$\rho \quad$ Density of fluid $\left(\mathrm{kg} / \mathrm{m}^{3}\right)$

$\mathrm{H} \quad$ Height of square duct $(\mathrm{mm})$

$\mathrm{S} \quad$ Width of square duct $(\mathrm{mm})$

$Y \quad$ Pitch of twisted tape $(\mathrm{mm})$

$w \quad$ Width of twisted tape $(\mathrm{mm})$

$P \quad$ Pressure $(\mathrm{Pa})$

$k \quad$ Thermal ConductivityW $/ \mathrm{m}{ }^{\circ} \mathrm{C}$

$U_{i} \quad$ Velocities in different Cartesian direction $(\mathrm{m} / \mathrm{s})$

$\vartheta \quad$ Kinematic viscosity $\left(\mathrm{m}^{2} / \mathrm{s}\right)$

$\alpha \quad$ Thermal Diffusivity $\left(\mathrm{m}^{2} / \mathrm{s}\right)$

$\mathrm{c}_{\mathrm{p}} \quad$ Specific Heat at Constant Pressure $(\mathrm{kJ} / \mathrm{kgK})$

$s_{\text {gen }} \quad$ Local entropy generation number $\left(\mathrm{W} / \mathrm{m}^{3} \mathrm{~K}\right)$

$\dot{s}_{T} \quad$ Entropy Generation Due to heat temperature Gradient $\left(\mathrm{W} / \mathrm{m}^{3} \mathrm{~K}\right)$

$\dot{s} \quad$ Entropy Generation due to Viscosity $\left(\mathrm{W} / \mathrm{m}^{3} \mathrm{~K}\right)$

$\varnothing \quad$ Viscous Dissipation Rate $\left(\mathrm{W} / \mathrm{m}^{3}\right)$

$N_{s, a} \quad$ Entropy augmentation generation number

NPR Non Parametric Regression

GA Genetic Algorithm

$\mu \mathrm{GA} \quad$ Micro Genetic Algorithm

Re Reynolds Number

EAGN Entropy Augmentation Generation Number

$\mathrm{T} \quad$ Time (s)

\section{REFERENCES}

[1] Sarma, P. K., Kishore, P. S., Rao, V. D., Subrahmanyam, T. (2005). A combined approach to predict friction coefficients and convective heat transfer characteristics in A tube with twisted tape inserts for a wide range of Re and Pr. International Journal of Thermal Sciences, 44(4), 393-398.

[2] Eiamsa-ard, S., Thianpong, C., Promvonge, P. (2006). Experimental investigation of heat transfer and flow friction in a circular tube fitted with regularly spaced twisted tape elements. International Communications in Heat and Mass Transfer, 33(10), 1225-1233.

[3] Eiamsa-Ard, S. (2010). Study on thermal and fluid flow characteristics in turbulent channel flows with multiple twisted tape vortex generators. International Communications in Heat and Mass Transfer, 37(6), 644-651.

[4] Eiamsa-Ard, S., Promvonge, P. (2007). Heat transfer characteristics in a tube fitted with helical screw-tape with/without core-rod inserts. International Communications in Heat and Mass Transfer, 34(2), 176-185. 
[5] Sundar, L. S., Sharma, K. V., \& Ramanathan, S. (2007). Experimental investigation of heat transfer enhancements with $\mathrm{Al} 2 \mathrm{O} 3$ nanofluid and twisted tape insert in a circular tube. International Journal of Nanotechnology and Applications, 1(2), 21-28.

[6] Sivashanmugam, P., Suresh, S. (2007). Experimental studies on heat transfer and friction factor characteristics of turbulent flow through a circular tube fitted with regularly spaced helical screw-tape inserts. Applied Thermal Engineering, 27(8-9), 1311-1319.

[7] Eiamsa-ard, S., Pethkool, S., Thianpong, C., \& Promvonge, P. (2008). Turbulent flow heat transfer and pressure loss in a double pipe heat exchanger with louvered strip inserts. International Communications in Heat and Mass Transfer, 35(2), 120-129.

[8] Kumar, A., Prasad, B. N. (2009). Enhancement in solar water heater performance using twisted tape inserts. National Journal of the Institution of Engineers, 90, 6-9.

[9] Al-Fahed, S., Chakroun, W. (1996). Effect of tube-tape clearance on heat transfer for fully developed turbulent flow in a horizontal isothermal tube. International journal of heat and fluid flow, 17(2), 173-178.

[10] Eiamsa-ard, S., Thianpong, C., Promvonge, P. (2006). Experimental investigation of heat transfer and flow friction in a circular tube fitted with regularly spaced twisted tape elements. International Communications in Heat and Mass Transfer, 33(10), 1225-1233.

[11] Jaisankar, S., Radhakrishnan, T. K., Sheeba, K. N. (2009). Experimental studies on heat transfer and friction factor characteristics of thermosyphon solar water heater system fitted with spacer at the trailing edge of twisted tapes. Applied Thermal Engineering, 29(5-6), 1224-1231.

[12] Pramanik D., Saha SK (2006).Thermohydraulics of laminar flowthrough rectangular and square ducts with transverse ribs andtwisted tapes. Trans ASME J Heat Transfer, 128, 1070-1080.

[13] Saha, S. K., Dutta, A., Dhal, S. K. (2001). Friction and heat transfer characteristics of laminar swirl flow through a circular tube fitted with regularly spaced twisted-tape elements. International Journal of Heat and Mass Transfer, 44(22), 4211-4223.

[14] Saha, S. K., Mallick, D. N. (2005). Heat transfer and pressure drop characteristics of laminar flow in rectangular and square plain ducts and ducts with twisted-tape inserts. Journal of heat transfer, 127(9), 966-977. [15] Pathipakka, G., Sivashanmugam, P. (2010). Heat transfer behaviour of nanofluids in a uniformly heated circular tube fitted with helical inserts in laminar flow. Superlattices and Microstructures, 47(2), 349-360.

[16] Nonino, C., Comini, G. (2002). Convective heat transfer in ribbed square channels. International Journal of Numerical Methods for Heat \& Fluid Flow, 12(5), 610-628.

[17] Konchada, P., Pv, V. Bhemuni, V. (2016). Statistical analysis of entropy generation in longitudinally finned tube heat exchanger with shell side nanofluid by a single phase approach. Archives of Thermodynamics, 37(2), 3-22).

[18] Zimparov, V. (2001). Enhancement of heat transfer by a combination of three-start spirally corrugated tubes with a twisted tape. International Journal of Heat and Mass Transfer, 44(3), 551-574.

[19] Zimparov, V. (2002). Enhancement of heat transfer by a combination of a single-start spirally corrugated tubes with a twisted tape. Experimental Thermal and Fluid Science, 25(7), 535-546.

[20] Bejan A., Pfister P.A. J r (1980). Evaluation of heat transfer augmentation techniques based on their impact on entropy generation.Lett. Heat Mass Transfer, 7, 97-106.

[21] Bejan A. (1982).Entropy Generation through Heat and Fluid Flow, Wiley, New York.

[22] Hesselgreaves J.E. (2000).Rationalisation of second law analysis of heat exchangers.Internat. J. Heat Mass Transfer, 43, 4189-4204.

[23] Zimparov V. (2001). Extended performance evaluation criteria for enhanced heat transfer surfaces: heat transfer through ducts with constant heat flux. International J. Heat Mass Transfer, 44, 169-180.

[24] Golberg, D. E. (1989). Genetic algorithms in search, optimization, and machine learning. Addion wesley, 1989(102), 36.

[25] D. Whitley (1993). A genetic algorithm tutorial.Colorado State University Technical Report CS-93-103.

[26] Razeghi, A., Mirzaee, I., Abbasalizadeh, M. et al. J Braz. Soc. Mech. Sci. Eng. (2017) 39: 2307 
[27] Al-Rashed , A. , Kolsi , L. , Hussein , A. K. , Hassen , W. , Aichouni , M. and Borjini. (2017). M. Numerical study of three-dimensional natural convection and entropy generation in a cubical cavity with partially active vertical walls , Case Studies in Thermal Engineering, 10,100-110.

[28] Kolsi , L. , Hussein, A.K. , Borjini, M. , Mohammed , H. and Ben Aïssia ,H.(2014). Computational analysis of three-dimensional unsteady natural convection and entropy generation in a cubical enclosure filled with water-A12O3 nanofluid, Arabian Journal for Science and Engineering , 39 ,7483-7493. 